\title{
Short-term dose and duration-dependent glucocorticoid risk for cardiovascular events in glucocorticoid-naive patients with rheumatoid arthritis
}

\author{
Anthony James Ocon (1) ,' George Reed, ${ }^{2,3}$ Dimitrios A Pappas 주 , 3,4,5 \\ Jeffrey R Curtis ${ }^{0}{ }^{6}{ }^{6}$ Joel M Kremer ${ }^{3,5,7}$
}

Handling editor Josef $\mathrm{S}$

Smolen

- Additional online supplemental material is published online only. To view, please visit the journal online (http://dx.doi.org/10.1136/ annrheumdis-2021-220577).

For numbered affiliations see end of article.

Correspondence to

Dr Anthony James Ocon, Allergy, Immunology, Rheumatology, University of Rochester Medical Center, Rochester, NY 14642, USA; anthony.ocon@gmail.com

Received 16 April 2021 Accepted 22 June 2021 Published Online First 2 July 2021

\section{ABSTRACT}

Objectives Rheumatoid arthritis (RA), along with glucocorticoid use, is associated with cardiovascular disease. Cardiovascular safety of glucocorticoids in RA is controversial and may be related to dose and duration of use. We determined if initiating glucocorticoids in steroid-naive RA patients would increase cardiovascular event (CVE) risk in a dose and duration-dependent manner over short-term intervals.

Methods Patients enrolled in CorEvitas (formerly Corrona) RA registry. Cox proportional-hazards models estimated adjusted HRs (aHR) for incident CVE in patients who initiated glucocorticoid treatment, adjusting for RA duration, traditional cardiovascular risk factors and time-varying covariates: Clinical Disease activity Index, disease-modifying antirheumatic drugs use and prednisone-equivalent use. Glucocorticoid use assessed current daily dose, cumulative dose and duration of use over rolling intervals of preceding 6 months and 1 year.

Results 19902 patients met criteria. 1106 CVE occurred (1.66/100 person-years). Increased aHR occurred at current doses of $\geq 5-9 \mathrm{mg} 1.56(1.18-2.06)$ and $\geq 10 \mathrm{mg} 1.91$ (1.31-2.79), without increased risk at $0-4 \mathrm{mg} 1.04$ (0.55-1.59). Cumulative dose over preceding 6 months showed increased aHR at 751$1100 \mathrm{mg} 1.43$ (1.04-1.98) and >1100 mg 2.05 (1.422.94), without increased risk at lower doses; duration of use over preceding 6 months exhibited increased aHR for $>81$ days of use 1.54 (1.08-2.32), without increased risk at shorter durations. One-year analyses were consistent. Conclusions Over preceding 6-month and 1-year intervals, initiating glucocorticoids in steroid-naïve RA patients is associated with increased risk of CVE at daily doses $\geq 5 \mathrm{mg}$ and increased cumulative dose and duration of use. No association with risk for CVE was found with daily prednisone of $\leq 4 \mathrm{mg}$ or shorter cumulative doses and durations.

Check for updates

(C) Author(s) (or their employer(s)) 2021. No commercial re-use. See rights and permissions. Published by BMJ.

To cite: Ocon AJ,

Reed G, Pappas DA

et al. Ann Rheum Dis

2021:80:1522-1529.

\section{INTRODUCTION}

Rheumatoid arthritis (RA) is a systemic autoimmune disease characterised by inflammatory destructive arthritis. Risk for cardiovascular disease (CVD) in $\mathrm{RA}$ is increased due to high prevalence of traditional risk factors, accelerated atherosclerosis and chronic inflammation. ${ }^{1}$ Disease activity is directly related to cardiovascular risk. ${ }^{2}$ Glucocorticoids (GCs) are commonly prescribed as initial, so-called bridge, treatment for RA but are often employed

\section{Key message}

What is already known about this subject?

- Both rheumatoid arthritis (RA) and glucocorticoid use increase risk for cardiovascular events. There is controversy regarding the cardiovascular safety and risk of glucocorticoid use in RA patients. Effects of short-term and low-dose use are not well understood.

What does this study add?

- In a large, real-word clinical registry of patients with long-standing disease, there is a daily dose, cumulative dose and duration of use glucocorticoid threshold for cardiovascular event risk in RA when analysed over short-term intervals of 6 months and 1 year.

- Relative cardiovascular safety was found with $<5 \mathrm{mg}$ of prednisone-equivalent daily dose and lower cumulative doses and durations of use.

How might this impact on clinical practice or future developments?

- Physicians should be aware of that low-dose and short-term use of glucocorticoids may increase risk of cardiovascular events when prescribing for treatment of RA in a treat-totarget approach.

- Patient education of this risk threshold is essential.

for intervals that extend beyond the onset of action of other conventional, targeted synthetic or biological disease-modifying antirheumatic drugs (cs/ ts/bDMARDs). ${ }^{3}$ It is often clinically challenging to taper GC. However, GCs are associated with CVD and may potentiate hypertension, hyperlipidaemia, diabetes mellitus, congestive heart failure and obesity. ${ }^{4-6}$ Given that CVD is the major comorbidity of RA, ${ }^{12}$ the juxtaposition of these circumstances presents a therapeutic dilemma.

Controversy exists regarding the risks and benefits of GC in RA patients. Previous small studies demonstrated an increased number of adverse events in RA patients over longer intervals with a daily prednisone-equivalent doses of $>5$ to $10 \mathrm{mg}^{7-10}$ However, debate remains regarding the detrimental 
cardiovascular effects of GC therapy in RA patients. ${ }^{11-16}$ Relative cardiovascular safety is generally assumed with lower dose and shorter durations of use, especially over short-term intervals. However, little data has actually been reported regarding the temporal effects of short-term interval GC use preceding cardiovascular events (CVE).

The 2016 and 2019 European League Against Rheumatism and 2015 and 2021 American College of Rheumatology (ACR) recommend the use of 'low-dose' GC for 'the least amount of time' in combination with DMARDs for the treatment of RA. ${ }^{37-19}$ Thus, it is important to determine the safety of initiating 'low-dose' GC in regard to the development of CVE. Furthermore, CVE in RA may be decreasing due to better control of disease activity following the widespread use of ts/bDMARDs, perhaps making the determination of the contribution of GC to CVE even more challenging in the present era. ${ }^{20}$

We, therefore, examined the CorEvitas (formerly Corrona) RA registry, a longitudinal database of RA patients, to determine whether there was a relationship between CVE in RA and use of GC in the dose ranges and duration of use that are consistent with published guidelines and routine clinical practice. We sought to determine the relative safety or risk for incident CVE in steroid-naïve patients who initiate 'low-dose' GC over shortterm intervals of use based on real-world clinical observation, while adjusting for traditional cardiovascular risk factors, RA duration and disease activity and cs/ts/bDMARD use. Given the ubiquitous use of GC in this and other inflammatory conditions in a variety of dose ranges, including what is considered 'low-dose,' it was both timely and appropriate to reexamine this association.

\section{METHODS}

\section{Study Cohort Entry Criteria}

The CorEvitas (formerly Corrona) RA registry was previously described. $^{21} 22$ Inclusion criteria included age $\geq 18$ years old and receiving a diagnosis of RA by a rheumatologist. ${ }^{23}$ Data were collected between 1 October 2001 and 31 March 2018. During this period, 48535 patients enrolled. Exclusion criteria included: any history of current or past GC therapy at or prior to enrolment; absence of a follow-up visit; missing data for either gender, age or duration of RA; or patients that had >15 months between visits. Patients were treated per their rheumatologist without treatment assignment.

\section{Data collection}

Observational data were collected from both treating physicians and patients at registry enrolment and at regular intervals consistent with the frequency of scheduled visits occurring every 2-9 months (median 4.6 months, IQR 3.60-6.24). At enrolment, detailed medical history was obtained from patients and review of medical records to accurately document lifetime comorbidities and prior treatments and medication use, including GC use.

\section{Measure of GC use}

GC use after entry into the registry was documented as equivalent milligrams of prednisone. Multiple measures of GC use were assessed. Current daily dose was defined as the most recent recorded dose at the time of a CVE or the most recent recorded dose in the registry for patients without an event. Cumulative total dose was defined as the summation of prednisone-equivalent dosage updated at each visit in a continuous, rolling manner over the preceding 6 months or 1 year (see online appendix efigure 1). Duration of use was defined as the summation of the absolute number of days a patient was treated with GC in a rolling manner over the preceding 6 months or 1 year (see online appendix efigure 1 ). Interval ranges for daily and cumulative dose were chosen based on equivalent quartiles of patient-time. Quartiles of duration of use were also chosen to have intervals with equal numbers of patient-time in each.

\section{Event definition and documentation}

For this study, CVE were defined as cardiac death, myocardial infarction, stroke, hospitalisation for hypertension, coronary revascularisation procedures, ventricular arrhythmia, unstable angina, congestive heart failure, transient ischaemic attacks, deep vein thrombosis (DVT), peripheral arterial thromboembolic event, urgent peripheral arterial revascularisation, peripheral arterial ischaemia, pulmonary embolism (PE), acute coronary syndrome or 'other' event. 'Other' events included complex or overlapping events, other arrythmias or conduction abnormality, cardiomyopathy, unspecified coronary artery disease, or events the reporting physician felt more comfortable categorising as 'other' if there was potential overlap with category choices provided.

At follow-up visits, both physician and patient-derived clinical data were updated in detail, including medication and dose changes for GC and cs/ts/bDMARDs. ${ }^{22}$ Incident comorbidities and targeted medical events, including CVE, were specifically ascertained and collected at each visit by the treating rheumatologist (see online appendix file 1). After the receipt of a report of CVE on the registry form, the site then completed a separate e-form with deidentified primary hospital or cardiologist records confirming and validating the event with description of specific drugs and dose used for treatment (see online appendix efigure $2) .{ }^{24}$ These forms were reviewed to confirm and validate the event, and ensure that it had not been previously reported, with any duplicate events excluded. In addition, a physician could report an event between formal registry visits. Finally, CVE, in particular CV death, were also reported on registry exit form. Any event that was not confirmed and validated was excluded.

\section{Data analysis}

The registry enrolment visit date was the index date. Only the first CVE following enrolment was used. Missing data for covariates were carried forward from the prior visit. If missing GC dose at a visit occurred, the prior dose was carried forward.

Time to first CVE was modelled using Cox proportionalhazards regression models to estimate unadjusted and adjusted HR and 95\% CIs. Our model computed cumulative dose or duration of use over the preceding 6 months or 1 year at every daily time point from the index date to the last time point for each patient. This last time point could be a CVE, last registry visit, or dropout from the registry, whichever occurred first. At each time point, the model compared the risk of a CVE in patients at each quartile of prednisone use (current dose, cumulative dose, duration of use) to the risk in patients with no use.

For the adjusted analysis, baseline covariables in the model included age, sex, race, duration of RA, history of CV disease, diabetes mellitus, hyperlipidaemia, hypertension, statin use, NSAID use, tobacco use, year of enrolment, baseline modified Health Assessment Questionnaire score (mHAQ) and the baseline Clinical Disease Activity Index (CDAI) for RA. The CDAI is a validated disease activity metric that includes tender and swollen joints (28 joint count), as well as physician and patient evaluation of global arthritis activity on a 10-point Visual Analogue Scale. ${ }^{25}$ Additionally, time-varying covariates in the 
model included measures of prednisone use as described above, NSAID use, cs, b, tsDMARDS and CDAI, which were updated at each follow-up visit.

A sensitivity analysis excluded all venous thromboembolisms (DVT and/or PE) as CVE to determine if excluding venous events impacted risk. A different sensitivity analysis excluded all patients with prior history of a CVE to assess whether this comorbidity had influenced risk. Another sensitivity analysis excluded 'other' CVE to assess its influence on the outcomes of interest.

Student's t-test or $\chi^{2}$ test compared data at baseline. All analyses were generated using Stata V.16.1 (StataCorp).

\section{RESULTS}

\section{Sample characteristics}

A total of 19902 patients (41\%) met entry criteria. Exclusions occurred as follow: 21162 patients had prior history of prednisone use; 5059 patients had no follow-up; 42 patients were missing information regarding use of prednisone; 1672 patients had time between visits of $>15$ months; 743 patients had missing information for covariates (age, gender, duration of RA, smoking status, CDAI and/or mHAQ).

For the 19902 who met criteria, the follow-up included 66436 patient-years and 127674 follow-up visits over $>16$ years. Of these patients, $2500(12.6 \%)$ initiated GC during the follow-up. Median time to first use in the registry was 19 months (IQR: 9.1-38.4) after enrolment.

\section{Assessment of CVE risk with initiating GC use}

A total of 1106 CVE occurred, yielding a rate of 1.66 CVE per 100 patient-years (95\% CI 1.57 to 1.77 ). As depicted in table 1 of unadjusted enrolment characteristics prior to any CVE and follow-up interval, patients who developed CVE had a greater prevalence of traditional CV risk factors, more severe RA, and were more likely to use csDMARD. Table 2 displays the frequency of each CVE.

Table 3 displays unadjusted and adjusted HR for daily and cumulative dose and duration of GC use over the preceding 6 month and 1 year intervals. Online appendix table 1 shows the number of patients contributing time to each category. Unadjusted current daily dose of $<5 \mathrm{mg}$ was not associated with increased risk, while doses $\geq 5 \mathrm{mg}$ increased risk in a doseresponse manner. Figure 1 demonstrates the adjusted risk of CVE based on daily prednisone-equivalent dose with similar findings.

As shown in table 3 , cumulative doses of $>750 \mathrm{mg}$ over the preceding 6 months were associated with increased unadjusted risk for developing a CVE. Figure 2 shows the risk for developing a CVE remained for cumulative doses of $>750 \mathrm{mg}$ after adjustment for covariates. In both unadjusted and adjusted analyses, cumulative doses $\leq 750 \mathrm{mg}$ were not associated with increased risk. Also shown in table 3, cumulative doses of $>1110 \mathrm{mg}$ over the preceding 1 year were associated with significant increased unadjusted risk for developing a CVE. Figure 2 shows this risk remained for cumulative doses of $>1100 \mathrm{mg}$ after adjustment for covariates. In both unadjusted and adjusted analyses, cumulative doses $\leq 1100 \mathrm{mg}$ over the preceding 1 -year were not associated with increased risk.

As shown in table 3, GC use for $>80$ days over the preceding 6 months interval was associated with increased unadjusted risk for developing a CVE. Shorter use than 80 days was not associated with increased risk. Figure 3 illustrates similar risk when adjusted for covariates. Over the preceding 1-year interval, a similar, if less smooth, increased unadjusted (table 3 ) and adjusted (figure 2) risk for a CVE after 100 days of use was found.

\section{Sensitivity analyses}

Online appendix table 2 shows the results of the sensitivity analysis when DVT and PE were excluded. With exclusion of DVT/ PE, 1007 CVE occurred. Results were similar to the primary analysis.

Online appendix table 3 shows the results of the sensitivity analysis when a history of prior CVE was excluded. With this exclusion, the total number of patients was 18 168, with 2300 initiating prednisone. There were $829 \mathrm{CVE}$ in this analysis. Results were similar to the primary analysis.

Online appendix table 4 shows the results of the sensitivity analysis when 'other' CVE were excluded. With this exclusion, 817 events occurred. The results were similar to the primary analysis.

\section{DISCUSSION}

We report, for the first time, that the relative cardiovascular safety or risk of initiating GC in a real-world clinical sample of steroid-naïve RA patients with longstanding disease at registry enrolment is associated with a threshold daily dose, cumulative dose, and duration of use when analysed over short-term intervals of the preceding 6 months or 1 year. The risk for CVE increased directly with increasing current daily dose, with the greatest estimated risk at $\geq 5-9 \mathrm{mg}$ and $\geq 10 \mathrm{mg}$ of prednisoneequivalents. Similarly, the risk for CVE increased in a doseresponse manner with increasing cumulative dose over these short-term intervals of analysis. The risk for CVE based on duration of use found increased risk after 80-days of use over the preceding 6 months and 100-days over the preceding 1 year in the dose ranges reported. There is 'noise' in the duration of use data, especially over the preceding 1 year, and it is possible that this is due to a threshold effect related to dose. That is, the duration of use analysis does not necessarily account for dose; thus, similar durations of use may have different total doses, especially with longer use. Of additional clinical importance, we found no increased risk for CVE with current prednisone-equivalent daily doses of $<5 \mathrm{mg}$ or cumulative doses of $\leq 750 \mathrm{mg}$ over the preceding 6 months or $\leq 1100 \mathrm{mg}$ over the preceding 1 year. We found no increased risk with duration of use $\leq 80$ days over the preceding 6 months or $\leq 100$ days over the preceding 1 year. It is critically important to note that these findings remained after adjustment for established cardiovascular risk factors, RA duration, disease activity and cs/ts/bDMARDs.

These novel insights can be immediately employed in clinical practice. The methodology of our analysis allows the application to patients based on their most recent 6 months or 1 year GC use. We believe that our data demonstrate that GC use should be tapered to a dose of $<5 \mathrm{mg}$ prednisone-equivalents as expeditiously as possible, while being aware of duration of use and cumulative dose. Thus, clinicians should provide counselling and education of these findings when encountering a reluctance on the part of a pain-free patient to taper GC, or succumb to the temptation to simply increase the dose to make the patient feel better until their next visit.

Both the IMPROVED and CareRA trials established that GCs can be tapered in patients with early RA in a protocolised, supervised, investigational regimen. ${ }^{26} 27$ Verschueren et al also reported on a supervised step-down GC taper in 19 patients with early RA. ${ }^{28}$ The observational data we report on in patients 


\section{Rheumatoid arthritis}

Table 1 Unadjusted sample characteristics stratified by development of a cardiovascular event (CVE) measured at registry enrolment*

\begin{tabular}{|c|c|c|c|c|c|}
\hline \multirow[b]{2}{*}{ Variable } & \multicolumn{2}{|c|}{ No CVE (N=18796) } & \multicolumn{2}{|c|}{ CVE $(N=1106)$} & \multirow[t]{2}{*}{$P$ value } \\
\hline & Mean & SD & Mean & SD & \\
\hline Age (years) & 57.82 & 13.36 & 65.44 & 11.07 & $<0.001$ \\
\hline Duration of rheumatoid arthritis (years) & 8.84 & 9.42 & 11.56 & 10.76 & $<0.001$ \\
\hline mHAQ & 0.32 & 0.42 & 0.38 & 0.47 & $<0.001$ \\
\hline CDAl & 12.73 & 12.50 & 14.04 & 12.84 & 0.001 \\
\hline 28 Joint Count: Tender & 3.93 & 5.81 & 4.44 & 6.39 & 0.005 \\
\hline 28 Joint Count: Swollen & 3.81 & 5.39 & 4.18 & 5.33 & 0.028 \\
\hline Patient Global Assessment (0-100 scale) & 28.95 & 26.08 & 31.71 & 26.44 & 0.001 \\
\hline Physician Global Assessment (0-100 scale) & 21.76 & 20.38 & 23.75 & 20.53 & 0.002 \\
\hline \multirow[t]{2}{*}{ Body mass index $\left(\mathrm{kg} / \mathrm{m}^{2}\right)$} & 29.44 & 7.14 & 29.60 & 7.00 & 0.468 \\
\hline & $\mathrm{N}$ & $\%$ & $\mathrm{~N}$ & $\%$ & \\
\hline Gender & & & & & $<0.001$ \\
\hline Male & 4134 & 22.0 & 369 & 33.4 & \\
\hline Female & 14662 & 78.0 & 737 & 66.6 & \\
\hline Race & & & & & 0.202 \\
\hline Asian & 286 & 1.5 & 12 & 1.1 & \\
\hline Black & 1184 & 6.3 & 55 & 5 & \\
\hline Mixed race & 223 & 1.2 & 14 & 1.3 & \\
\hline Native American & 122 & 0.6 & 6 & 0.5 & \\
\hline Other & 105 & 0.6 & 3 & 0.3 & \\
\hline Pacific Islander & 21 & 0.1 & 2 & 0.2 & \\
\hline Unknown & 132 & 0.7 & 3 & 0.3 & \\
\hline White & 16723 & 89.0 & 1011 & 91.4 & \\
\hline History of cardiovascular disease & & & & & $<0.001$ \\
\hline Yes & 1457 & 7.8 & 277 & 25.0 & \\
\hline History of diabetes & & & & & $<0.001$ \\
\hline Yes & 1502 & 8.0 & 176 & 15.9 & \\
\hline History of hyperlipidaemia & & & & & $<0.001$ \\
\hline Yes & 4154 & 22.1 & 333 & 30.1 & \\
\hline History of hypertension & & & & & $<0.001$ \\
\hline Yes & 5583 & 29.7 & 511 & 46.2 & \\
\hline Smoking status & & & & & 0.001 \\
\hline Never & 11330 & 60.3 & 604 & 54.6 & \\
\hline Previous & 4946 & 26.3 & 339 & 30.7 & \\
\hline Current & 2520 & 13.4 & 163 & 14.7 & \\
\hline Exercise & & & & & $<0.001$ \\
\hline None & 5879 & 31.3 & 390 & 35.3 & \\
\hline 1-2 times/week & 5313 & 28.3 & 277 & 25.0 & \\
\hline 3-4 times/week & 4054 & 21.6 & 213 & 19.3 & \\
\hline 5-6 times/week & 1376 & 7.3 & 68 & 6.1 & \\
\hline Daily & 1748 & 9.3 & 141 & 12.7 & \\
\hline Not sure & 426 & 2.3 & 17 & 1.5 & \\
\hline Statin use & & & & & $<0.001$ \\
\hline Yes & 3750 & 20.0 & 303 & 27.4 & \\
\hline NSAID use & & & & & 0.024 \\
\hline Yes & 10272 & 54.6 & 643 & 58.1 & \\
\hline Analgesic use & & & & & $<0.001$ \\
\hline Yes & 8516 & 45.3 & 565 & 51.1 & \\
\hline Prior or current biologic/targeted DMARD use & & & & & 0.815 \\
\hline Yes & 8633 & 45.9 & 504 & 45.6 & \\
\hline Prior or current conventional DMARDs & & & & & $<0.001$ \\
\hline Yes & 16447 & 87.5 & 1019 & 92.1 & \\
\hline Prior or current methotrexate use & & & & & $<0.001$ \\
\hline Yes & 14027 & 74.6 & 893 & 80.7 & \\
\hline
\end{tabular}

*Patients were enrolled with prevalent disease.

CDAl, Clinical Disease Activity Index; DMARDs, disease-modifying antirheumatic drugs; mHAQ, modified Health Assessment Questionnaire; NSAID, non-steroidal antiinflammatory drug. 


\begin{tabular}{|c|c|c|}
\hline Events & Frequency & Per cent \\
\hline Acute coronary syndrome & 3 & 0.27 \\
\hline Cardiac arrest & 19 & 1.72 \\
\hline Congestive heart failure & 106 & 9.58 \\
\hline Cardiovascular death & 8 & 0.72 \\
\hline Deep vein thrombosis & 83 & 7.5 \\
\hline Hospitalisation for hypertension & 16 & 1.45 \\
\hline Myocardial infarction & 117 & 10.58 \\
\hline Other cardiovascular event* & 289 & 26.13 \\
\hline Peripheral arterial event & 4 & 0.36 \\
\hline Peripheral arterial intervention & 3 & 0.27 \\
\hline Pulmonary embolism & 26 & 2.35 \\
\hline Coronary revascularisation & 204 & 18.44 \\
\hline Stroke & 136 & 12.3 \\
\hline Transient ischaemic attack & 51 & 4.61 \\
\hline Unstable angina & 16 & 1.45 \\
\hline Urgent peripheral arterial revascularisation & 1 & 0.09 \\
\hline Ventricular arrhythmia & 24 & 2.17 \\
\hline Total events & 1106 & 100 \\
\hline
\end{tabular}

${ }^{*}$ Other events included the following: complex or overlapping events (eg, acute coronary syndrome with coronary revascularisation), atrial fibrillation, other supraventricular arrhythmia, unspecified bradycardia, other unspecified conduction abnormality, new but stable angina, unspecified coronary artery disease, cardiac syncope or orthostatic hypotension, cardiomyopathy, other cardiac interventional procedure, abdominal aortic aneurysm, other peripheral arterial disease or cardiac event not otherwise specified.

with longstanding disease are perhaps more representative of a general population of RA patients on GC.

It should also be noted that we stratified our subject sample to see how subjects who developed CVE differed at the baseline time of registry enrolment from those who did not (table 1). Those who developed CVE were older, had more traditional CVD risk factors, greater disease activity, longer disease duration, and more commonly were on non-bDMARDs. Again,

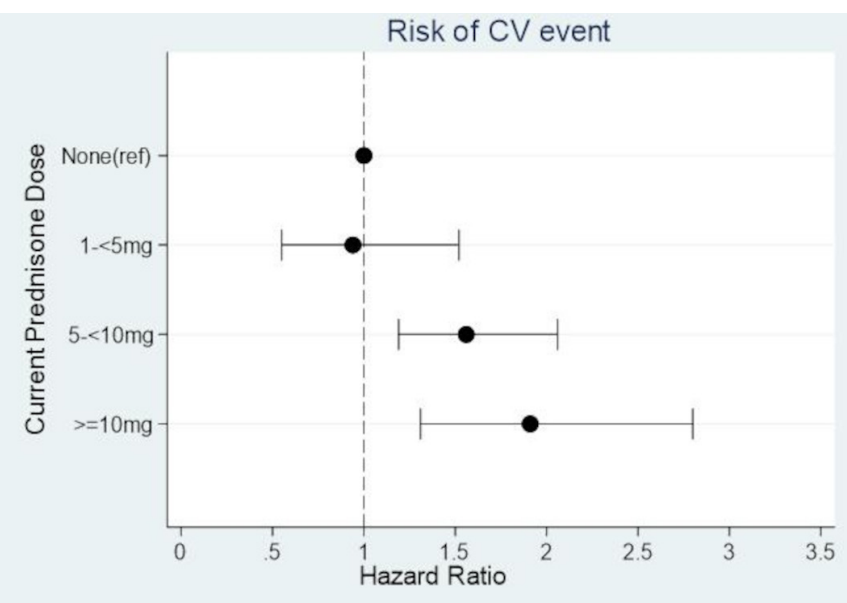

Figure 1 Adjusted risk of cardiovascular (CV) event associated with current daily prednisone-equivalent dose. There is a threshold for increased risk of an event. Prednisone-equivalent doses of 5-9 mg and $\geq 10 \mathrm{mg}$ were associated with an increased risk. However, doses $<5 \mathrm{mg}$ were not associated with increased risk. The risk was adjusted for traditional CV risk factors, rheumatoid arthritis disease activity and duration, and cs/ts/bDMARD use. cs/ts/bDMARD, conventional, targeted synthetic or biological disease-modifying antirheumatic drugs.
Table 3 Unadjusted and adjusted HRs for cardiovascular (CV) event with initiating glucocorticoid use

\begin{tabular}{|c|c|c|}
\hline Daily dose $(\mathrm{mg}) \dagger$ & Unadjusted HR $(95 \% \mathrm{Cl})$ & Adjusted* HR $(95 \% \mathrm{Cl})$ \\
\hline None & 1 (ref) & 1 (ref) \\
\hline $1-<5$ & 1.04 (0.61 to 1.76$)$ & 0.94 (0.55 to 1.59 ) \\
\hline$\geq 5-9$ & 1.78 (1.35 to 2.35$)$ & 1.56 (1.18 to 2.05$)$ \\
\hline$\geq 10$ & 2.09 (1.44 to 3.05$)$ & 1.91 (1.31 to 2.79 ) \\
\hline Cumulative dose $(\mathrm{mg}) \dagger$ & Unadjusted HR (95\% CI) & Adjusted $^{*} \mathrm{HR}(95 \% \mathrm{Cl})$ \\
\hline \multicolumn{3}{|l|}{ Over preceding 6 months: } \\
\hline None & 1 (ref) & 1 (ref) \\
\hline $1-380$ & 0.93 (0.56 to 1.50$)$ & $0.86(0.53$ to 1.40$)$ \\
\hline $381-750$ & 1.31 (0.88 to 1.95$)$ & 1.20 (0.81 to 1.79 ) \\
\hline $751-1100$ & 1.62 (1.18 to 2.24$)$ & 1.43 (1.04 to 1.98$)$ \\
\hline$>1110$ & 2.25 (1.57 to 3.22 ) & 2.05 (1.42 to 2.94$)$ \\
\hline \multicolumn{3}{|l|}{ Over preceding 1 year: } \\
\hline None & 1 (ref) & 1 (ref) \\
\hline $1-500$ & 0.99 (0.64 to 1.54$)$ & 0.93 (0.60 to 1.45$)$ \\
\hline $501-1100$ & 1.28 (0.89 to 1.83 ) & 1.19 (0.83 to 1.70$)$ \\
\hline $1101-2100$ & 1.63 (1.18 to 2.25$)$ & 1.47 (1.06 to 2.03 ) \\
\hline$>2100$ & 1.97 (1.41 to 2.74$)$ & 1.74 (1.25 to 2.43$)$ \\
\hline Duration of use (days) & Unadjusted HR (95\% CI) & Adjusted $^{*} \mathrm{HR}(95 \% \mathrm{Cl})$ \\
\hline \multicolumn{3}{|l|}{ Over preceding 6 months: } \\
\hline None & 1 (ref) & 1 (ref) \\
\hline $1-80$ & 0.77 (0.46 to 1.29$)$ & 0.72 (0.60 to 1.45$)$ \\
\hline $81-160$ & 1.66 (1.16 to 2.36$)$ & 1.54 (1.08 to 2.20$)$ \\
\hline $161-181$ & 1.71 (0.76 to 3.81 ) & 1.56 (0.70 to 3.48$)$ \\
\hline$>181$ & 1.79 (1.38 to 2.35$)$ & 1.57 (1.20 to 2.05$)$ \\
\hline \multicolumn{3}{|l|}{ Over preceding 1 year: } \\
\hline None & 1 (ref) & 1 (ref) \\
\hline $1-100$ & 1.08 (0.72 to 1.62$)$ & 1.02 (0.68 to 1.53$)$ \\
\hline $101-220$ & 1.50 (1.10 to 2.05$)$ & 1.41 (1.03 to 1.93$)$ \\
\hline $221-360$ & 0.99 (0.60 to 1.62 ) & 0.88 (0.54 to 1.44$)$ \\
\hline$>360$ & 2.15 (1.59 to 2.92 ) & 1.88 (1.39 to 2.56$)$ \\
\hline
\end{tabular}

*Adjusted for age, sex, race, duration of RA, history of CV disease, diabetes mellitus, hyperlipidaemia, hypertension, statin use, NSAID use, tobacco use, year of enrolment, baseline modified health assessment questionnaire score, CDAI and cs, $b$, tsDMARDS use.

tPrednisone-equivalents.

CDAl, Clinical Disease Activity Index; cs/ts/bDMARDs, conventional, targeted synthetic or biological disease-modifying antirheumatic drugs; NSAID, non-steroidal anti-inflammatory drug; RA, rheumatoid arthritis.

adjustment for these factors found an independent association with GC use.

The methodology of our investigation expands on the prior literature. Both Saag et al and Davis et al studied adverse events, including CVE, in RA patients receiving GC. ${ }^{710}$ However, there are numerous differences in methodology of the present investigation including the historical therapeutic interval and duration of observation, ${ }^{10}$ robustness of numbers, as well as specific focus on CVE. Our adjustment for multiple confounding variables further distinguishes our approach from prior studies that did not adjust for all these variables. ${ }^{8} 9$ 29-32 Our findings provide context beyond these prior studies by highlighting the relative cardiovascular safety of doses of GCs $\leq 4 \mathrm{mg}$ daily over the 6-month interval described. ${ }^{18} 33$ Our findings also add evidence to the EULAR and ACR task force recommendations for steroid taper. ${ }^{19}{ }^{34}$ Huscher et al also reported a threshold for GC side effects in RA patients without examining CVE. ${ }^{35}$

Others have looked at the effects of short-term GC use. George et al reported on the effect of dosages on serious infectious events (SIEs) using a Medicare claims database. ${ }^{36}$ They found a 


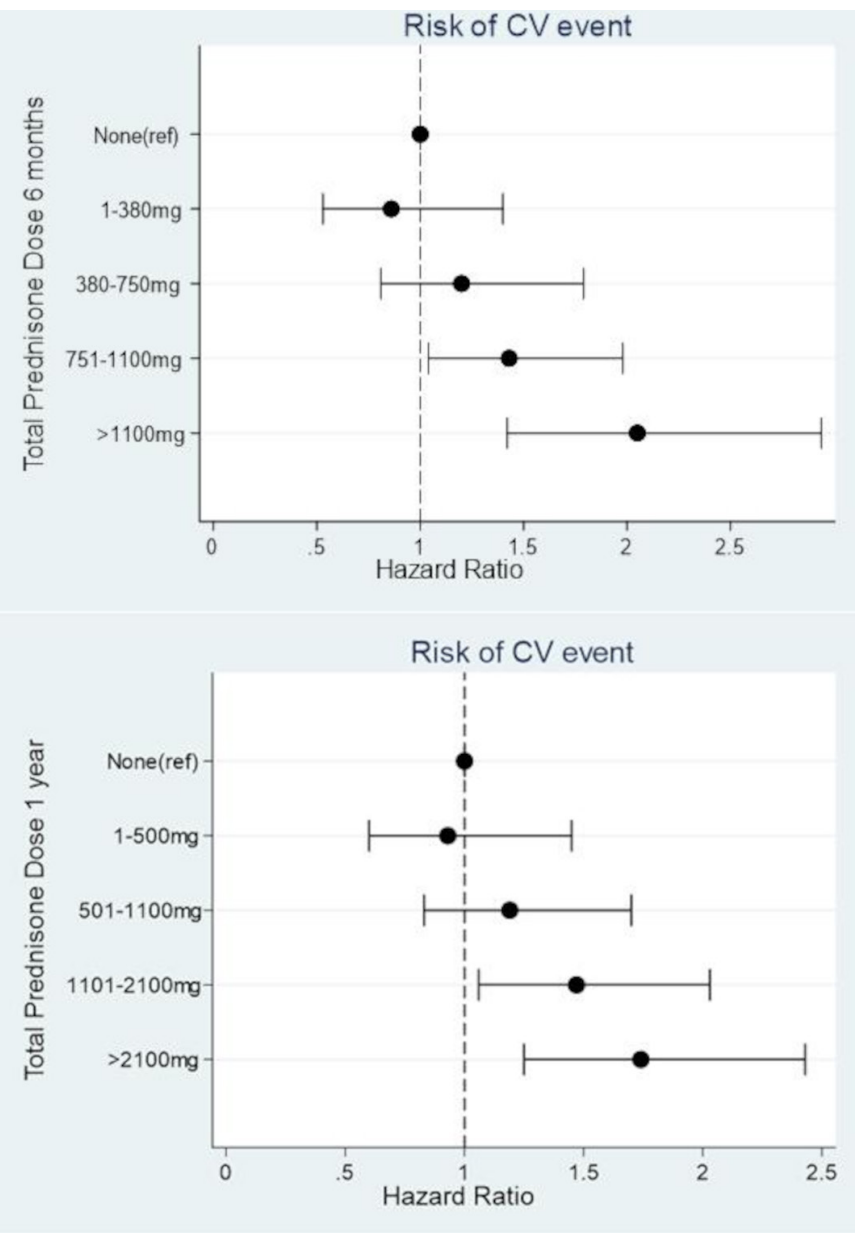

Figure 2 Top: adjusted risk of cardiovascular (CV) events associated with total glucocorticoid use over preceding 6 month interval. Bottom: adjusted risk of CV event associated with total glucocorticoid use over preceding 1-year interval. There was a dose-response increase in risk for CV event. Over the preceding 6 months of use, cumulative prednisoneequivalent doses of 751-1100 mg and $>1100 \mathrm{mg}$ were associated with increased risk for a CV event. Over the preceding 1 year of use, cumulative doses of 1101-2011 mg and >2100 mg were associated with increased risk for a CV event. This risk was adjusted for traditional CV risk factors, rheumatoid arthritis disease activity and duration, and $\mathrm{cs} / \mathrm{ts} / \mathrm{bDMARD}$ use. cs/ts/bDMARD, conventional, targeted synthetic or biological disease-modifying antirheumatic drugs.

robust relationship of SIEs with increasing doses, although they were not able to determine the effect of actual disease activity. Similarly, Yao et al used a national insurance database to assess the effects of short 'burst' courses ( $\leq 14$-days) of prednisone on incident adverse events of gastrointestinal (GI) bleeding, sepsis, and heart failure at 5-30 days and 31-90 days from use, finding a higher incidence rate of these events at both time points in the general population who used prednisone. ${ }^{37}$ Together, the findings of these studies of predominantly non-cardiac adverse events support our conclusion that detrimental effects of GC are strongly associated with short-term intervals preceding the event.

Our study has several additional strengths. Our investigation spanned a 16-year period, while prior studies were based much shorter duration of observation. ${ }^{89} 29-3238-40$ The data were derived from over 700 participating sites of real-world clinical observation in the USA The protocol independently confirmed and validated events with hospital records. We then analysed


Figure 3 Top: adjusted risk of cardiovascular (CV) event associated with total duration of use of glucocorticoids over preceding 6-month interval. Bottom: adjusted risk of CV event associated with total duration of use of glucocorticoids over preceding 1-year interval. There was a duration of use threshold for increased risk. Over the preceding 6 months, prednisone-equivalent use for $\geq 81$ days was associated with an increased risk for a CV event. Over the preceding 1 year, use for $101-220$, and $>360$ days was associated with an increased risk for a CV event, with trend towards increased risk between 221 and 260 days. The risk was adjusted for traditional cardiovascular risk factors, rheumatoid arthritis disease activity and duration, and cs/ts/bDMARD use. cs/ ts/bDMARD, conventional, targeted synthetic or biological diseasemodifying antirheumatic drugs.

reported events, not limiting to MACE, increasing the real-world clinical relevance for practising physicians. We excluded prevalent and past GC users, in an effort to minimise the effect of past use. Sensitivity analyses demonstrated that having a history of prior CVE, venous-related events, or the 'other' category of CVE did not influence the results, a particularly important design feature of our analysis. ${ }^{41} 42$

Our study is not without limitations. Patients in observational registries are treated without assignment of interventions. Although we adjusted for multiple confounding factors, there is still a risk of channelling bias or residual confounding. While GC dose and usage were updated in the registry at each visit, there is potential for patient reporting to be limited by recall bias. However, the percentage of patients we studied without prior GC use at the time of registry enrolment (41\%) is similar to that reported in the ARAMIS registry, supporting our robust data collection methods. ${ }^{43}$ It is not clear whether our findings are 
applicable to early RA patients treated with GC since our cohort contained predominantly RA patients with longer disease duration. A similar observational analysis of the success of GC taper in early RA patients not participating in a supervised protocol would be of interest.

A possible limitation of this report is that we were not able to adjust our findings for time-varying changes in $\mathrm{C}$ reactive protein, which is a known risk factor for CVE, or for either rheumatoid factor or anticitrullinated protein antibody status as laboratory values are not mandated in this observational registry. However, we adjusted for other traditional cardiovascular risk factors, as well as time-varying changes in actual RA disease activity measured at the time of each registry visit. As is the case with long-term observational data, the cohort of patients at different time points may differ as patients enter and exit the registry. The risk was established with a very large number of patients over very long observational intervals that greatly increased our statistical power. Nevertheless, assignment of risk to a specific individual may not be appropriate. In addition, with any statistical association, we cannot determine causality with absolute certainty. While a prospective randomised controlled trial of GC dosing would be ideal, it is highly unlikely that this kind of trial will ever be conducted given the pragmatic challenges with the number of patients required, study duration, funding, ethics, and other challenges associated with the complete absence of steroid use in a control group.

In conclusion, we reported that daily doses of $\geq 5 \mathrm{mg}$ of prednisone-equivalents, elevated cumulative dose and extended duration of use of GC over the preceding 6-month and 1-year intervals are associated with an increased risk for incident CVE in steroid-naïve patients with RA. We also emphasise the relative absence of CVE with dosing of $\leq 4 \mathrm{mg}$ per day, lower cumulative dose and a duration of use of only 6 months prior to an event. Physicians treating patients with RA should consider these threshold ranges of GC use when prescribing prednisone as a part of a treat-to-target regimen.

\section{Author affiliations \\ 'Medicine and Allergy, Immunology, Rheumatology, University of Rochester Medical Center, Rochester, New York, USA \\ ${ }^{2}$ Medicine, Preventative and Behavioral Medicine, University of Massachusetts Medical School, Worcester, Massachusetts, USA \\ ${ }^{3}$ Corrona Research Foundation, LLC, Waltham, MA, USA \\ ${ }^{4}$ Medicine and Rheumatology, Columbia University, New York, New York, USA \\ ${ }^{5}$ CorEvitas (formerly CORRONA), LCC, Waltham, Massachusetts, USA \\ ${ }^{6}$ Department of Medicine, University of Alabama at Birmingham, Birmingham, Alabama, USA \\ ${ }^{7}$ Medicine and Rheumatology, Albany Medical College, The Center for Rheumatology, LLC, Albany, New York, USA}

Contributors AJO and JMK designed the study. Statistical analysis by GR. All authors (AJO, GR, DAP, JRC and JMK) participated in data interpretation, writing, editing and final approval.

Funding The investigation was funded by the Corrona Research Foundation, a not for profit, $501(\mathrm{C})(3)$ independent charitable foundation, with no industry financial ties

Competing interests AJO has no financial conflicts of interest. GR and JMK are consultants for Corrona, LLC. GR is a consultant for the Corrona Research Foundation (CRF), while JMK is an officer of the CRF who serves without any form of remuneration. The CRF is a not for profit, 501(C)(3) independent charitable foundation, with no industry financial ties. DAP is an employee and shareholder of Corrona, and a consultant for Regeneron, Novartis and Roche (unrelated work), and is a member of the board of directors for CFR. JRC has research grants and/or consulting from Abbvie, Amgen, Corrona, Janssen, Lilly, Pfizer, Sanofi (for unrelated work).

Patient and public involvement statement Patients were involved upon signing informed consent to participate in the registry, understanding that information would be recorded longitudinally and used for a variety of research outcomes that could be relevant to care. Patients were informed about the time required to complete forms at each visit. Outcomes of CorEvitas studies are shared with patients when viewed as potentially impacting their welfare. Patients were not involved in the design of or recruitment for this study.

Patient consent for publication Not required.

Ethics approval New England Institutional Review Board, ID number 120160610. All patients gave written informed consent.

Provenance and peer review Not commissioned; externally peer reviewed.

Data availability statement Data may be obtained from a third party and are not publicly available. Deidentified participant data may be obtained from CorEvitas (formerly Corrona) and are not publicly available. Reuse only with permission from CorEvitas.Contact: info@corevitas.com

Supplemental material This content has been supplied by the author(s). It has not been vetted by BMJ Publishing Group Limited (BMJ) and may not have been peer-reviewed. Any opinions or recommendations discussed are solely those of the author(s) and are not endorsed by BMJ. BMJ disclaims all liability and responsibility arising from any reliance placed on the content. Where the content includes any translated material, BMJ does not warrant the accuracy and reliability of the translations (including but not limited to local regulations, clinical guidelines, terminology, drug names and drug dosages), and is not responsible for any error and/or omissions arising from translation and adaptation or otherwise

\section{ORCID iDs}

Anthony James Ocon http://orcid.org/0000-0003-2903-5429

Dimitrios A Pappas http://orcid.org/0000-0001-8338-027X

Jeffrey R Curtis http://orcid.org/0000-0002-8907-8976

\section{REFERENCES}

1 Jagpal A, Navarro-Millán I. Cardiovascular co-morbidity in patients with rheumatoid arthritis: a narrative review of risk factors, cardiovascular risk assessment and treatment. BMC Rheumatol 2018;2:10.

2 Solomon DH, Reed GW, Kremer JM, et al. Disease activity in rheumatoid arthritis and the risk of cardiovascular events. Arthritis Rheumatol 2015;67:1449-55.

3 Singh JA, Saag KG, Bridges SL, et al. 2015 American College of rheumatology guideline for the treatment of rheumatoid arthritis. Arthritis Care Res 2016;68:1-25

4 Fardet L, Fève B. Systemic glucocorticoid therapy: a review of its metabolic and cardiovascular adverse events. Drugs 2014;74:1731-45.

5 Roubille C, Martel-Pelletier J, Davy J-M, et al. Cardiovascular adverse effects of antiinflammatory drugs. Antiinflamm Antiallergy Agents Med Chem 2013;12:55-67.

6 Wei L, MacDonald TM, Walker BR. Taking glucocorticoids by prescription is associated with subsequent cardiovascular disease. Ann Intern Med 2004;141:764-70.

7 Saag KG, Koehnke R, Caldwell JR, et al. Low dose long-term corticosteroid therapy in rheumatoid arthritis: an analysis of serious adverse events. Am J Med 1994;96:115-23.

8 Sihvonen S, Korpela M, Mustonen J, et al. Mortality in patients with rheumatoid arthritis treated with low-dose oral glucocorticoids. A population-based cohort study. J Rheumatol 2006:33:1740-6.

9 del Rincón I, Battafarano DF, Restrepo JF, et al. Glucocorticoid dose thresholds associated with all-cause and cardiovascular mortality in rheumatoid arthritis. Arthritis Rheumatol 2014;66:264-72

10 Davis JM, Maradit Kremers H, Crowson CS, et al. Glucocorticoids and cardiovascular events in rheumatoid arthritis: a population-based cohort study. Arthritis Rheum 2007:56:820-30

11 Hafström I, Rohani M, Deneberg S, et al. Effects of low-dose prednisolone on endothelial function, atherosclerosis, and traditional risk factors for atherosclerosis in patients with rheumatoid arthritis--a randomized study. J Rheumatol 2007:34:1810-6.

12 Mazzantini M, Torre C, Miccoli M, et al. Adverse events during longterm lowdose glucocorticoid treatment of polymyalgia rheumatica: a retrospective study. $J$ Rheumatol 2012:39:552-7.

13 van Everdingen AA, Jacobs JWG, Siewertsz Van Reesema DR, et al. Low-Dose prednisone therapy for patients with early active rheumatoid arthritis: clinical efficacy, disease-modifying properties, and side effects: a randomized, double-blind, placebocontrolled clinical trial. Ann Intern Med 2002;136:1-12.

14 Ruyssen-Witrand A, Fautrel B, Saraux A, et al. Cardiovascular risk induced by low-dose corticosteroids in rheumatoid arthritis: a systematic literature review. Joint Bone Spine 2011;78:23-30.

15 Solomon DH, Greenberg J, Curtis JR, et al. Derivation and internal validation of an expanded cardiovascular risk prediction score for rheumatoid arthritis: a consortium of rheumatology researchers of North America registry study. Arthritis Rheumatol 2015:67:1995-2003.

16 Da Silva JAP, Jacobs JWG, Kirwan JR, et al. Safety of low dose glucocorticoid treatment in rheumatoid arthritis: published evidence and prospective trial data. Ann Rheum Dis 2006;65:285-93. 
17 Smolen JS, Landewé R, Bijlsma J, et al. EULAR recommendations for the management of rheumatoid arthritis with synthetic and biological disease-modifying antirheumatic drugs: 2016 update. Ann Rheum Dis 2017;76:960-77.

18 Smolen JS, Landewé RBM, Bijlsma JWJ, et al. EULAR recommendations for the management of rheumatoid arthritis with synthetic and biological disease-modifying antirheumatic drugs: 2019 update. Ann Rheum Dis 2020;79:685-99.

19 Fraenkel L, Bathon JM, England BR. 2021 American College of rheumatology guideline for the treatment of rheumatoid arthritis. Arthritis Rheumatol 2021.

20 Arts EE, Fransen J, Den Broeder AA, et al. Low disease activity (DAS28 3 3.2) reduces the risk of first cardiovascular event in rheumatoid arthritis: a time-dependent COX regression analysis in a large cohort study. Ann Rheum Dis 2017;76:1693-9.

21 Kremer JM. The CORRONA database. Autoimmun Rev 2006;5:46-54.

22 Kremer JM. The Corrona us registry of rheumatic and autoimmune diseases. Clin Exp Rheumatol 2016;34:S96-9.

23 Arnett FC, Edworthy SM, Bloch DA, et al. The American rheumatism association 1987 revised criteria for the classification of rheumatoid arthritis. Arthritis Rheum 1988;31:315-24.

24 Pappas DA, Nyberg F, Kremer JM, et al. Prevalence of cardiovascular disease and major risk factors in patients with rheumatoid arthritis: a multinational cross-sectional study. Clin Rheumatol 2018;37:2331-40.

25 Aletaha D, Nell VPK, Stamm T, et al. Acute phase reactants add little to composite disease activity indices for rheumatoid arthritis: validation of a clinical activity score. Arthritis Res Ther 2005;7:R796-806.

26 Akdemir G, Heimans L, Bergstra SA, et al. Clinical and radiological outcomes of 5-year drug-free remission-steered treatment in patients with early arthritis: improved study. Ann Rheum Dis 2018;77:111-8.

27 Stouten V, Westhovens R, Pazmino S, et al. Five-Year treat-to-target outcomes after methotrexate induction therapy with or without other csDMARDs and temporary glucocorticoids for rheumatoid arthritis in the CareRA trial. Ann Rheum Dis 2021:80:965-73.

28 Verschueren P, Esselens G, Westhovens R. Daily practice effectiveness of a stepdown treatment in comparison with a tight step-up for early rheumatoid arthritis. Rheumatology 2008;47:59-64.

29 Movahedi M, Costello R, Lunt M, et al. Oral glucocorticoid therapy and all-cause and cause-specific mortality in patients with rheumatoid arthritis: a retrospective cohort study. Eur J Epidemiol 2016;31:1045-55.

30 Nadareishvili Z, Michaud K, Hallenbeck JM, et al. Cardiovascular, rheumatologic, and pharmacologic predictors of stroke in patients with rheumatoid arthritis: a nested, case-control study. Arthritis Rheum 2008;59:1090-6.
31 Solomon DH, Avorn J, Katz JN, et al. Immunosuppressive medications and hospitalization for cardiovascular events in patients with rheumatoid arthritis. Arthritis Rheum 2006;54:3790-8.

32 Wolfe F, Michaud K. The risk of myocardial infarction and pharmacologic and nonpharmacologic myocardial infarction predictors in rheumatoid arthritis: a cohort and nested case-control analysis. Arthritis Rheum 2008;58:2612-21.

33 Luís M, Freitas J, Costa F, et al. An updated review of glucocorticoid-related adverse events in patients with rheumatoid arthritis. Expert Opin Drug Saf 2019;18:581-90.

34 Strehl C, Bijlsma JWJ, de Wit M, et al. Defining conditions where long-term glucocorticoid treatment has an acceptably low level of harm to facilitate implementation of existing recommendations: viewpoints from an EULAR Task force Ann Rheum Dis 2016;75:952-7.

35 Huscher D, Thiele K, Gromnica-Ihle E, et al. Dose-Related patterns of glucocorticoidinduced side effects. Ann Rheum Dis 2009:68:1119-24.

36 George MD, Baker JF, Winthrop K, et al. Risk for serious infection with low-dose glucocorticoids in patients with rheumatoid arthritis : A cohort study. Ann Intern Med 2020;173:870-878

37 Yao T-C, Huang Y-W, Chang S-M, et al. Association between oral corticosteroid bursts and severe adverse events : A nationwide population-based cohort study. Ann Intern Med 2020;173:325-30.

38 Ajeganova S, Svensson B, Hafström I, et al. Low-Dose prednisolone treatment of early rheumatoid arthritis and late cardiovascular outcome and survival: 10-year follow-up of a 2-year randomised trial. BMJ Open 2014;4:e004259.

39 Aviña-Zubieta JA, Abrahamowicz M, Choi HK, et al. Risk of cerebrovascular disease associated with the use of glucocorticoids in patients with incident rheumatoid arthritis: a population-based study. Ann Rheum Dis 2011;70:990-5.

40 Gonzalez-Gay MA, Gonzalez-Juanatey C, Lopez-Diaz MJ, et al. Hla-Drb1 and persistent chronic inflammation contribute to cardiovascular events and cardiovascular mortality in patients with rheumatoid arthritis. Arthritis Rheum 2007;57:125-32.

41 Costello RE, Yimer BB, Roads $\mathrm{P}$, et al. Glucocorticoid use is associated with an increased risk of hypertension. Rheumatology 2021;60:132-9.

42 Curtis JR, Westfall AO, Allison J, et al. Population-Based assessment of adverse events associated with long-term glucocorticoid use. Arthritis Rheum 2006;55:420-6.

43 Chester Wasko M, Dasgupta A, Ilse Sears G, et al. Prednisone use and risk of mortality in patients with rheumatoid arthritis: moderation by use of disease-modifying antirheumatic drugs. Arthritis Care Res 2016;68:706-10. 